\title{
AMYOTROPHIC LATERAL SCLEROSIS

\author{
CLINICAL ANALYSIS OF 78 CASES FROM \\ FORTALEZA (NORTHEASTERN BRAZIL)
}

\author{
CARLOS M. DE CASTRO-COSTA*, REINALDO B. ORIÁ*, JOÃO A. MACHADO-FILHO*, \\ MARIA T. G. FRANCO*, DÉBORA L. O. DINIZ*, SILVIO D. GIFFONI*, TEREZINHA J. T. SANTOS*, \\ FRANCISCO M. B. DA CUNHA*, VERALICE S. DE BRUIN*, CARLOS A. C. TEIXEIRA*
}

\begin{abstract}
We report on the clinical characteristics of amyotrophic lateral sclerosis (ALS) in Fortaleza (Northeastern Brazil). For this, we analyzed retrospectively (from 1980 to 1999) 78 cases of ALS from the Service of Neurology of the University Hospital of Fortaleza diagnosed clinically and laboratorially (EMG, muscle biopsy, myelography, blood biochemistry, muscle enzymes and cranio-cervical X-ray). The results showed that they were mostly sporadic ALS $(76 / 78)$, and they were divided into definite $(n=36)$, probable $(n=20)$, possible $(\mathrm{n}=15)$ and suspected $(\mathrm{n}=7)$, according to the level of diagnostic certainty. They were also subdivided into juvenile $(n=17)$, early-onset adult $(n=18)$, age-specific $(n=39)$ and late-onset $(n=4)$ groups. Clinically, they presented as initials symptoms, principally, asymmetrical (30/78) and symmetrical (24/78) weakness of extremities, besides bulbar signs, fasciculations, and atrophy. Curiously, pain as first symptom occurred in an expressive fashion (17/78). The predominant initial anatomic site, in this series, was the spinal cord, and mainly affecting the arms. As to the symptom accrual from region to region, this occurs more quickly in contiguous areas, and fasciculations are predominant when bulbar region was associated.
\end{abstract}

KEY WORDS: ALS, sporadic, early-onset, pain, anatomy, symptom accrual, fasciculations.

\section{Esclerose lateral amiotrófica: análise clínica de 78 casos de Fortaleza (Nordeste Brasileiro)}

RESUMO - Descrevemos as características clínicas da esclerose lateral amiotrófica (ELA) em Fortaleza (Nordeste Brasileiro). Para isso, fizemos uma análise retrospectiva (de 1980 a 1999) de 78 casos de ELA do Serviço de Neurologia do Hospital Universitário de Fortaleza, diagnosticados do ponto de vista clínico e laboratorial (EMG, biópsia de músculo, mielografia, análises hematológica e bioquímica, e raio $\mathrm{X}$ da junção crânio-cervical). Os resultados mostraram que esses casos eram principalmente da forma esporádica (76/78), e estes foram divididos, de acordo com o nível de certeza diagnóstica, em definidos $(n=36)$, prováveis $(n=20)$, possíveis $(n=15)$ e suspeitos $(n=7)$. Eles foram também subdivididos nos grupos juvenil $(n=17)$, adulto jovem $(n=18)$, idadeespecífico $(n=39)$ e tardio $(n=4)$. Clinicamente, os principais sintomas iniciais foram fraqueza assimétrica $(38 /$ 78) e simétrica (24/78) das extremidades, além de sinais bulbares, fasciculações e atrofia. Curiosamente, dor como sintoma inicial ocorria de maneira expressiva (17/78). O local anatômico inicial predominante foi, nessa série, a medula espinhal, afetando principalmente os braços. O avanço regional de sintomas ocorreu mais rapidamente em áreas contíguas, e as fasciculações eram predominantes quando a região bulbar estava associada.

PALAVRAS-CHAVE: ELA, esporádica, início precoce, dor, anatomia, avanço dos sintomas, fasciculações.

Amyotrophic lateral sclerosis (ALS) is a condition of undetermined cause, which affects the anterior horn cells and the corticospinal tract.

The etiology is manifold so that different causes have been proposed such as virus/slow virus (polio virus, HIV) prions, environmental factors (heavy metals, low levels of calcium and magnesium,

Service of neurology (University Hospital) / Laboratory of Experimetal Neurology (Department of Physiology and Pharmacology), Federal University of Ceará (UFC), Brazil. aceite: 18-junho-1999.

Dr. Carlos Maurício de Castro Costa - Lab. de Neurologia Experimental e Neurofisiologia/DFF/UFC - Rua Cel. Nunes de Melo, 1127 -60430-270 Fortaleza CE - Brasil . Fax 5585243 9333. E-mail: pst016@ sec.secrel.com.br 
excitotoxic and neurotoxic agents (such as $\beta$-N-methylamino-L-alanine (BMAA) and metylazomethanol- $\beta$-D-glucoside (cycasin)), lead, mercury, aluminium), abnormal calcium metabolism, immunological dysfunction (presence of Bence-Jones protein, cell mediated immunity to poliovirus antigens, circulating immune complexes $)^{1-3}$. Moreover, mutation in the copper/zinc superoxide dismutase gene (SOD-1) in a subset of 10 to $20 \%$ of familial ALS cases and excitotoxicity (glutamate) are also shown as factors involved in the genesis of ALS ${ }^{1,4}$. ALS is clinically expressed by focal and multifocal weakness, atrophy, cramps and fasciculations, associated with the corticospinal tract signs of spasticity and enhanced pathologic reflexes in the absence of sensory findings. The cortico-bulbar tracts may be involved, resulting in dysphagia and dysarthria ${ }^{4}$.

The mechanisms involved in the clinical expression of ALS are centred on molecular events that lead to degeneration of motor neurons. These events include overstimulation of excitatory aminoacid receptors (NMDA or AMPA and kainate) which allow an excess of intracellular calcium entry and a cascade of processes that culminate in neuronal death. Moreover, the mutation of SOD-1 inhibits its protective action against oxidative neurotoxicity of superoxide ions and reactive species (peroxynitrite and hydroxyl radicals), and induces apoptosis of motor neuron ${ }^{4-6}$. The immunological mechanisms of ALS genesis also rest upon calcium channels disturbance due to the reaction of immunoglobulin to these receptors ${ }^{7}$. Nitric oxide is a potentially lethal toxin in the nervous system. Its release from neurons is mediated by glutamate stimulation of NMDA receptors, what results in calcium influx, which activates nitric oxide synthase, converting arginine to citrulline and leading to nitric oxide release. In the presence of elevated extracellular glutamate, nitric oxide levels became lethal, leading to neuronal death ${ }^{8}$.

The criteria for diagnosis of ALS have been defined by the World Federation of Neurology (WFN $)^{9}$ and have guided the definition of this condition in the different studies from then on. ALS is a universal disease with common clinical characteristics in different parts of the world. However, nosographic analysis of a clinical entity may progressively add new findings and more details so that its natural history may outstand as a diagnostic definition mark. The perusal of Brazilian literature on ALS has shown a lack of clinical analysis of larger series of ALS. There is an interest in delineating the clinical characteristics of ALS in Brazil for the existence, in that part of the world, of ecological and populational characteristics that may possibly influence the clinical expression of pathologies.

This study aims at analyzing clinically a series of 78 ALS cases in order to depict peculiarities and universalities of the clinical expression of ALS in Fortaleza (Northeastern Brazil)

\section{METHOD}

We analyzed, retrospectively (from 1980 to 1999), 78 patients presenting symptoms and signs of ALS. Most of them were hospitalized for diagnosis definition in the University Hospital of Fortaleza, and in many of them, the following exams were performed: electromyography, nerve conduction velocity, muscle biopsy and myelography. In some patients, blood studies for cells and muscle enzymes were carried out. Due to frequent cases of basilar impression, X-ray of the cranio-cervical transition was also performed. Unfortunately, for economical reasons, advanced neuroimaging studies (MRI) were performed in only very few patients. Moreover, analysis of the cerebrospinal fluid was also done in some cases. Most of these cases did not return to Hospital and consequently were not followed-up, so that we could not determine prospective evolution and time of death. This will be subject of future work.

For ALS diagnosis, we have followed, as much as possible, the criteria proposed by the WFN, as shown below, and we have created a coding system with numbers, Greek letters and vocals for, in a summarized way, describing the neurological examination of the patients (see Tables):

1. The diagnosis of ALS require the presence of: a) Lower motor neuron signs ( $1 \alpha)$; b) Upper motor neuron signs $(1 \beta)$; c) Progression $(\gamma)$.

2. Absence of sensory signs, sphincter abnormalities, Parkinson's disease, Alzheimer's disease, other causes of ALS-like syndromes and anterior visual system abnormalities $(\delta)$. 
3. The diagnosis is supported by the presence of fasciculations (2a) in one or more regions or abnormalities in isokinetic / isometric strength tests, pulmonary function tests, speech tests, swallowing studies, muscle biopsy and normal nerve biopsy (2b).

4. This way, the diagnosis is divided into proven, definite, probable, possible and suspected cases.

4.1. The proven diagnosis is based upon post-mortem findings of lower and upper motor neuronal loss and atrophy, loss of Nissl substance, corticospinal tract degeneration and absence of other major central nervous system (CNS) abnormalities, extensive central chromatolysis, active neuronophagia, Alzheimer's neurofibrillary changes, abnormal storage material, significant spongiform changes and extensive inflammation;

4.2. The definite diagnosis includes upper and lower motor neuron signs in 3 regions (brainstem, cervical and lumbo-sacral), progression and supportive or exclusionary electrophysiological and laboratory tests (electromyography (EMG) and biopsy);

4.3. The probable diagnosis encompasses upper and lower motor neuron signs in 2 different regions, upper motor neuron signs rostral to lower motor neuron signs, progression and supportive or exclusionary electrophysiological and laboratory tests (EMG and biopsy);

4.4. The possible diagnosis consists of upper and lower motor neuron signs in 1 region or upper motor neuron signs in 2 or 3 regions, progression and supportive or exclusionary electrophysiological and laboratory tests (EMG and biopsy);

4.5. The suspected diagnosis is based on the presence of lower motor neuron signs in 2 or 3 regions, progression and supportive or exclusionary electrophysiological and laboratory tests (EMG and biopsy).

\section{RESULTS}

The clinical analysis of our series of 78 ALS patients, according to the "El Escorial" criteria (Table 1$)$, revealed that they were divided into definite $(n=36,46.1 \%)$, probable $(n=20,25.6 \%)$, possible $(n=15,19.2 \%)$ and suspected $(n=7,9 \%)$ levels of diagnostic certainty. Moreover, as to their age, they were subdivided into juvenile group between 15 and 29 years $(n=17,21.8 \%)$, an early-onset adult group between 30 and 39 years $(n=18,23.1 \%)$, an age-specific group between 40 and 69 years $(n=39$, $50 \%)$ and an late-onset group between 70 and 78 years $(n=4,5.1 \%)$ (Appendix).

We have not followed all the patients up to their death to depict a clear and definite evolution of them, excepting for only six. The analysis of these 6 cases showed that the mean time of evolution of their disease was of 2.5 years, and that clinically, 4 had definite and 2 probable ALS, 5 were male and 1 female, with a mean age of onset of 37.3 years. From these cases, 4 had predominant bulbar form.

Clinically, our ALS patients presented, as initial symptoms, symmetrical (24/78, 30.8\%) or asymmetrical $(30 / 78,38.5 \%)$ weakness, predominantly. Moreover, they presented bulbar signs (dysphagia, dysphonia and dysarthria) $(11 / 78,14.1 \%)$, fasciculations or cramps $(19 / 78,24.4 \%)$, pain $(17 / 78,21.8 \%)$, and atrophy $(10 / 78,12.8 \%)($ Fig 1$)$.

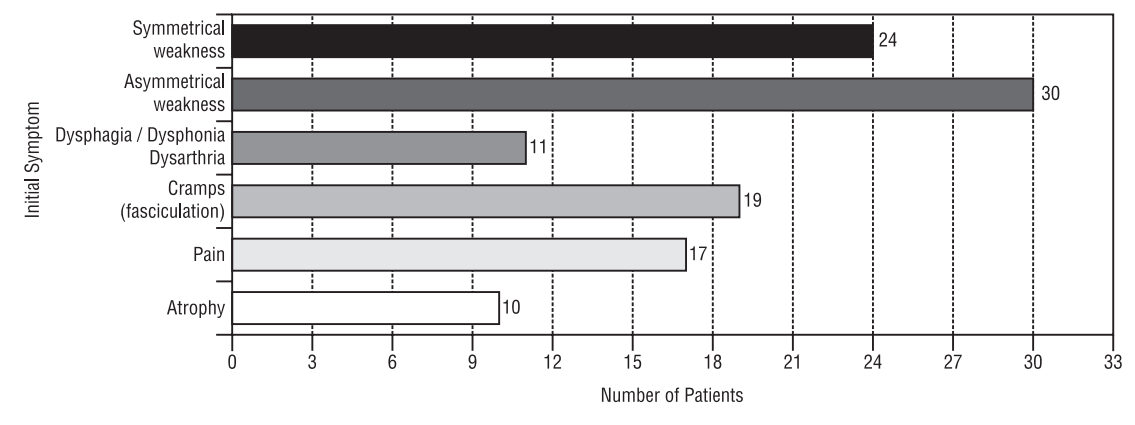

Fig 1. The initial symptoms in the 78 ALS patients from Fortaleza (Northeastern Brazil) between 1980 and 1999. The values are expressed in number of patients. 
Table 1. ALS subtypes with bulbar symptoms and anatomic body areas of onset correlated with gender and age.

\begin{tabular}{|c|c|c|c|c|c|c|c|c|}
\hline \multirow{2}{*}{$\begin{array}{l}\text { Subtype } \\
\text { Bulbar-onset }\end{array}$} & \multirow{2}{*}{$\begin{array}{l}\text { No. of } \\
\text { Cases }\end{array}$} & \multirow[t]{2}{*}{$\%$} & \multicolumn{3}{|c|}{ Gender } & \multicolumn{3}{|c|}{ Mean age } \\
\hline & & & Male & Female & Ratio & Male & Female & Total \\
\hline Dysphonia/Dysarthria & 02 & 2.6 & 02 & 00 & $2: 0$ & 62.5 & 0.0 & 62.5 \\
\hline Dysphonia/Dysphagia & 05 & 6.4 & 03 & 02 & $1.5: 1$ & 43.6 & 73.5 & 58.5 \\
\hline Dysphagia & - & - & - & - & - & - & - & - \\
\hline Total & 07 & 9 & 05 & 02 & $2.5: 1$ & 53.5 & 73.5 & 60.5 \\
\hline \multicolumn{9}{|l|}{ Spinal-onset } \\
\hline Right arm & 18 & 23.9 & 11 & 07 & $1.5: 1$ & 40.0 & 41.8 & 40.9 \\
\hline Left arm & 11 & 14.1 & 10 & 01 & 10:1 & 44.1 & 38.0 & 41.0 \\
\hline Right leg & 06 & 7.7 & 05 & 01 & $5: 1$ & 40.2 & 40.0 & 40.1 \\
\hline Left leg & 05 & 6.4 & 03 & 02 & $1.5: 1$ & 50.6 & 62.5 & 56.5 \\
\hline Right arm + leg & 01 & 1.3 & 01 & 00 & $1: 0$ & 18.0 & 0.0 & 18.0 \\
\hline Left arm + leg & 01 & 1.3 & 01 & 00 & $1: 0$ & 33.0 & 0.0 & 33.0 \\
\hline Both arms & 10 & 12.8 & 04 & 06 & $1: 1.5$ & 42.5 & 46.0 & 44.2 \\
\hline Both legs & 16 & 20.5 & 09 & 07 & $1.2: 1$ & 34.3 & 37.8 & 36.0 \\
\hline Three limbs & - & - & - & - & - & - & - & - \\
\hline Four limbs & 03 & 3.9 & 02 & 01 & $2: 1$ & 49.0 & 56.0 & 52.5 \\
\hline Total & 71 & 91 & 46 & 25 & $2.8: 1$ & 36.1 & 32.2 & 36.2 \\
\hline
\end{tabular}

The subtypes of ALS by anatomic areas of onset were the following: the bulbar-onset subtype comprised $9 \%(7 / 78)$ of the cases, distributed symptomatically with dysphonia/dysarthria $(2 / 78$, $2.6 \%)$ and dysphonia/dysphagia $(5 / 78,6.4 \%)$; the spinal-onset subtype comprised $91 \%(71 / 78)$ of the cases, so distributed as to the symptoms evolving from right arm $(18 / 78,23.1 \%)$, left arm (11/78, $14.1 \%)$, right leg $(6 / 78,7.7 \%)$, left leg $(5 / 78,6.4 \%)$, both arms $(10 / 78,12.8 \%)$ and both legs $(16 / 78$, $20.5 \%)$. Ipsilateral arm and leg onset was less expressive (2/78, $2.6 \%$ both), as well as concerning to four limbs $(3 / 78,3.9 \%)$ (Table 1, Fig 2a). These results showed that the predominant initial site in the 78 ALS patients of this series was the spinal cord $(71 / 78,91 \%)$ (Table 1, Figs. 2a and 2b). From these 78 patients, $39(50 \%)$ had initial symptoms in the arms, mainly in the right arm $(18 / 78,23.1 \%)$, what was followed by symptoms in the legs $(27 / 78,34.6 \%)$ and, in a lesser expression, in the bulbar region $(7 / 78,9 \%)$. Men predominated over women in both bulbar (5:2) and spinal-onset ALS (46:25). As to age, however, bulbar-onset ALS old patients were mainly women; conversely, somewhat older men predominated in spinal-onset ALS (Table 1). When men and women were taken into account as to bulbar and spinal-onset ALS, those of spinal-onset were younger than those with bulbar-onset ALS (Table 1).

Detailed analysis of symptoms development in 31 of these ALS patients from Fortaleza revealed the following aspects: the symptoms accrual from bulbar muscles to all limbs and to lower limbs, were, respectively, 6.5 and 14 months (total mean of 10.2 months). Conversely, from all limbs, upper limbs and lower limbs to bulbar muscles, the intervals were, respectively, 32.4, 14.8 and 15.3 months (total mean of 20.8 months). The symptom accrual between upper to lower limbs and lower to upper limbs was, respectively, of 6.5 and 14.7 months (total mean of 10.6 months). When limbs were considered separately, the symptom development from arm to contra-lateral arm and from leg to contra-lateral leg were, respectively, 11 and 6 months (total mean of 8.5 months), and from ipsilateral arm to leg and ipsilateral leg to arm were, respectively, 5 and 6 months (total 


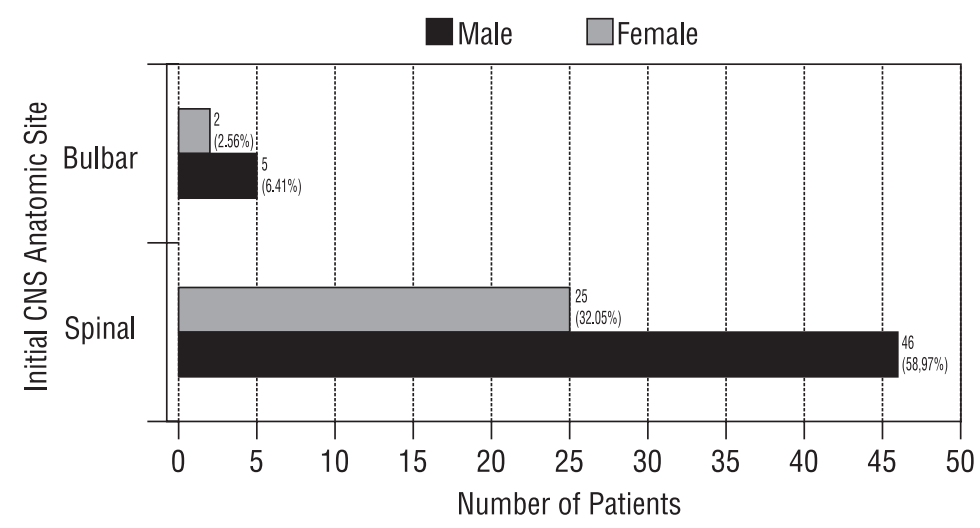

Fig 2a. The initial CNS anatomic site of lesion in the 78 ALS patients from Fortaleza (Northeastern Brazil) between 1980 and 1999. The values are expressed in number and percentage of patients.

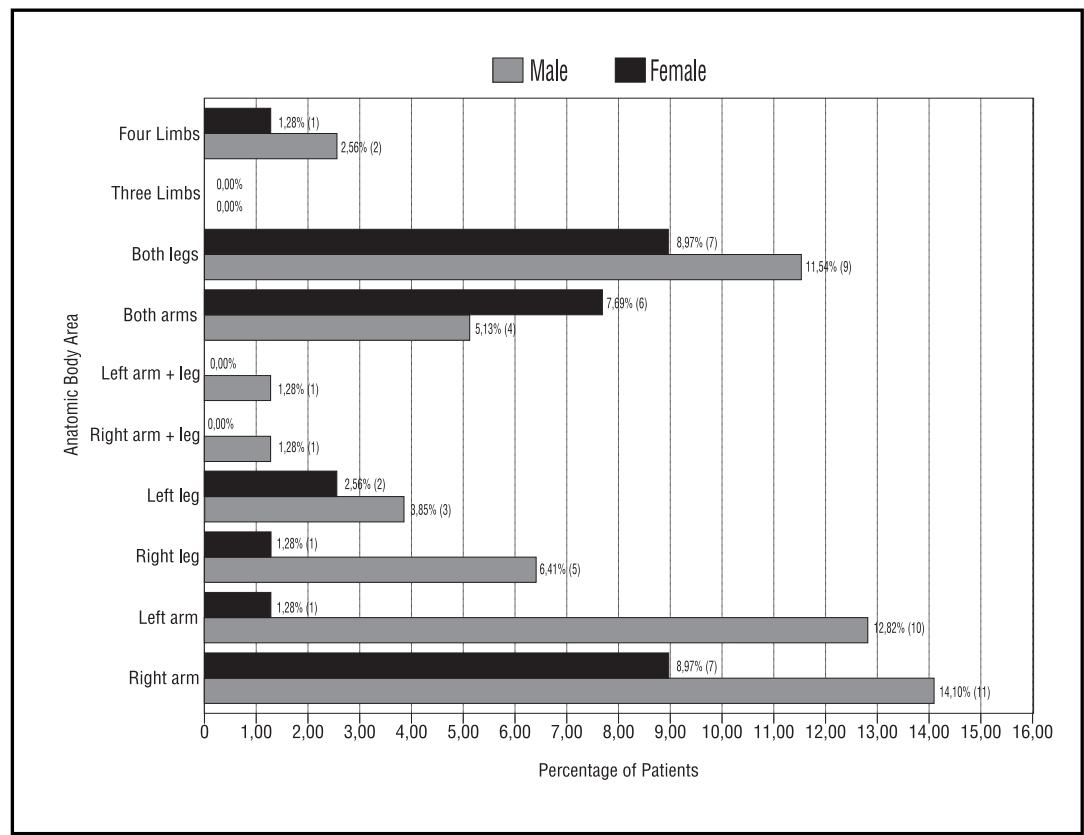

Fig $2 b$. The ALS subtype of spinal-onset by anatomic body area in the 78 ALS patients from Fortaleza (Northeastern Brazil) between 1980 and 1999. The values are expressed in number and percentage of patients.

mean of 5.5 months). In another approach, when considered arm to contra-lateral leg, the interval was of 16.5 months (Fig 3).

As isolated symptoms or signs, the analysis of the 78 ALS patients revealed a frequency of Babinski sign in 17 out 78 (21.8\%) of the patients, and fasciculations were distributed mainly involving bulbo-cervico-thoracic and lumbar segments (16/78, 20.5\%), bulbo-cervico-lumbar segments (13/ $78,16.7 \%)$, cervico-thoraco-lumbar segments $(11 / 78,14.1 \%)$, bulbo-cervical segments $(8 / 78,10.3 \%)$, 


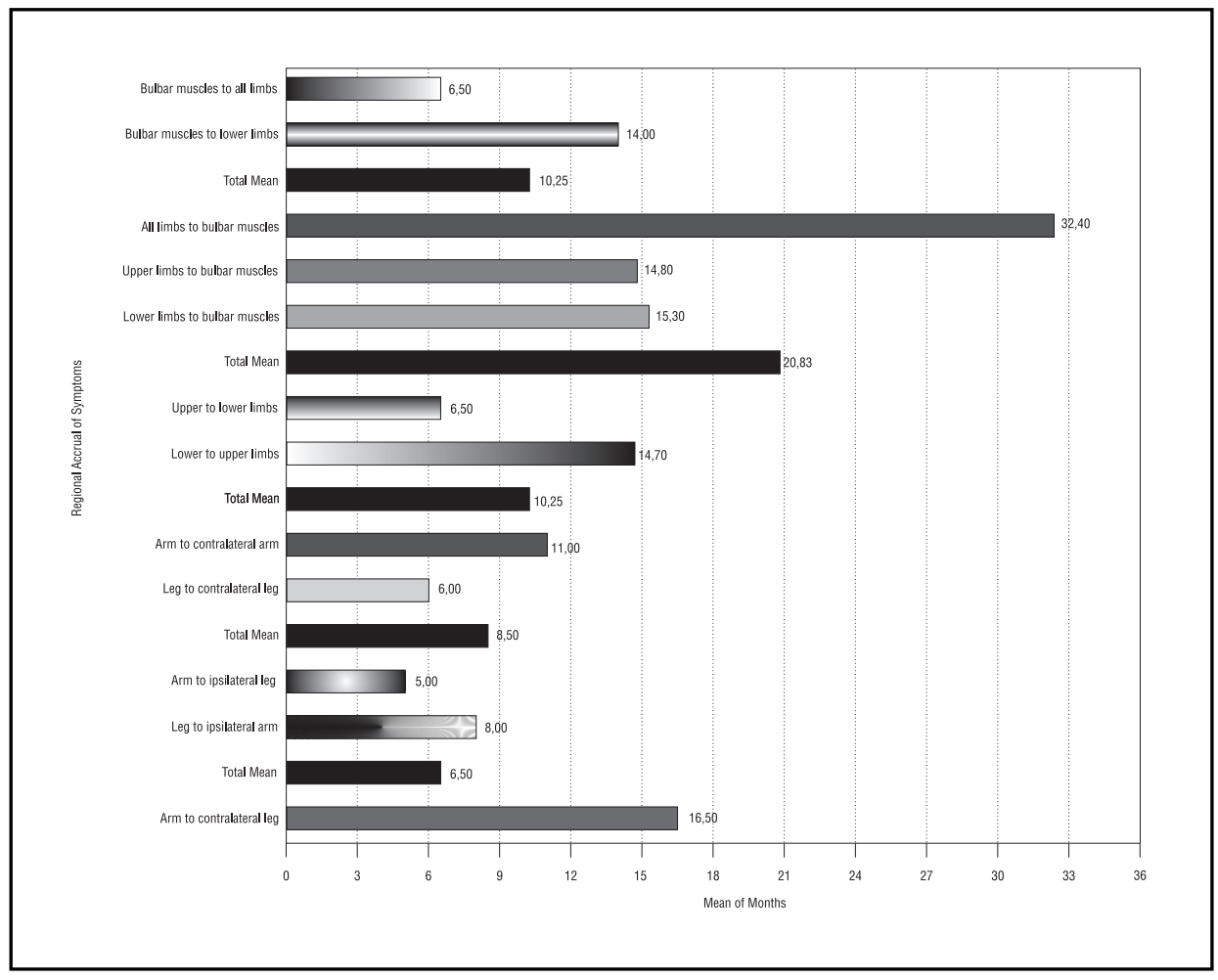

Fig 3. The accrual of symptoms from region to region in the 31 ALS patients from Fortaleza (Northeastern Brazil) between 1980 and 1999. The values are expressed in number and mean of months.

bulbar segment $(8 / 78,10.3 \%)$, bulbo-cervico-thoracic segment $(5 / 78,6.4 \%)$, cervical $(5 / 78,6.4 \%)$, cervico-lumbar $(3 / 78,3.8 \%)$, lumbar $(3 / 78,3.8 \%)$, bulbo-lumbar $(2 / 78,2.6 \%)$, cervico-thoracic (1/ $78,1.3 \%)$ and thoracic segments $(1 / 78,1.3 \%)$.

\section{DISCUSSION}

The clinical analysis of our ALS patients showed that most of them (71.8\%) were included in the definite and probable levels of diagnostic certainty, what reflects the evolutive degree of the disease and the level of the diagnostic investigation.

As to their age, it is surprising a percentage of $21.1 \%$ of sporadic juvenile cases in this region of Brazil, in comparison with northern areas of the world, where the percentage of those cases reaches only 0.5 to $2.3 \%^{10,11}$. The sporadic juvenile ALS is considered to be rare ${ }^{12-14}$, and in Brazil, excepting for an indirect report on some cases ${ }^{15}$, no established analysis of this occurrence has been carried out up to now. The meaning of this is still unclear, but the population curve trend in Brazil should be taken into account, since young people represent $46.5 \%$ of the Brazilian population, according to IBGE census of 1997 (Instituto Brasileiro de Geografia e Estatística, Brazilian Institute of Geography and Statistics).

According to the literature, the average survival of ALS patients s approximately of 3 years, with a duration ranging from 25 to 52 months $s^{16,17}$. Our small series of only 6 patients revealed concordant figures, with a mean duration of 2.5 years, and a median duration of 1 year, with a range of 12 to 72 months. Among these 6 patients, most of them had the bulbar-onset ALS (4/6, 66.7\%), what explain the 
poor prognosis they had $\mathrm{d}^{4,17}$. It is known that younger age of onset is associated with a better prognosis ${ }^{18}$. In this small series, the median age was of 46 years and the only 2 patients with longer survival had ages below 30 years, respectively 24 and 32 years. As to gender, the prognosis seems to be similar ${ }^{4}$.

Clinically, the majority of our patients presented asymmetrical muscle weakness as the first symptom, what is concordant with studies of larger series of patients ${ }^{10,17}$. Cramps or fasciculations as first symptoms were somewhat frequent in our patients, differently to the findings shown by Caroscio et al. ${ }^{10}$. Bulbar signs and atrophy were moderately expressed (11/78, 14.1\% and 10/78, $12.8 \%$, respectively), what differs from the results of Li et al.18. Surprisingly, in our series, $21.8 \%$ $(17 / 78)$ of the patients presented pain as first symptom. Sensory abnormalities were noted in only $2.5 \%$ of Li et al.' ${ }^{18}$ cases and pain has been reported to occur in $9 \%$ of ALS patients ${ }^{19}$. Pain in ALS patients may have, perhaps, different origins: it may be of nociceptive origin from involvement of other systems such as joints, muscles etc, or it may be of neuropathic origin due to deafferentation lesions of nociceptive neurons of posterior horn of the spinal cord as a consequence of motor neuron death, which received synaptic connection from these nociceptive neurons. Most frequently, pain in ALS is associated with reduced joint mobility, cramps and hypertonia ${ }^{4}$. However, pain in these patients is described as diffuse aching, burning and electric, or shocking-like in nature ${ }^{20}$, what points to its possible neuropathic origin.

The arms were the predominant initial site in our series (50\%), as shown in Li et al.'s ${ }^{18}$ and Brooks et al.' $\mathrm{s}^{21}$ series. This differs, however, from the series described by Caroscio et al. ${ }^{10}$, Jokelainen ${ }^{22}$, Gubbai et al. ${ }^{14}$ and Norris et al. ${ }^{23}$, where the legs were the initial affected part of the body. Subsequently, legs $(34.6 \%)$, and afterwards, bulbar muscles $(8.8 \%)$, were affected in our patients.

The analysis of symptoms development in our cases revealed that the speed of evolution increases more rapidly (10.2 months) from bulbar to spinal areas than when we consider spinal-onset ALS, where the evolution to bulbar region is much slower (around 20.8 months). This is correlated with duration and prognosis "quoad functionem et vitam". The prognosis of bulbar-onset ALS is poorer than that of spinal-onset ${ }^{4}$. However, this is not found in other series ${ }^{10}$. The evolution between upper and lower limbs shows that it is more rapid from upper to lower (6.5 months) than from lower to upper limbs (14.7 months). On the other hand, the evolution between arms and legs is different, and more rapid between legs (6 months). Moreover, there is a similar speed of evolution when the symptoms evolve from ipsilateral arm to leg and vice-versa (around 5.5 months) (Fig. 3). Similar results have been shown by Brooks et al. ${ }^{21}$, and corroborate the findings that neuronal degeneration occurs more quickly in contiguous areas and that rostral-caudal involvement is faster than caudal-rostral spread, possibly due to involvement of axonal transport ${ }^{21,24}$. Bulbar and spinal-onset ALS predominated in men in our series; moreover, when considered in any time of the evolution, this predominance of men over women persists. Nevertheless, Li et al. ${ }^{18}$ have shown a predominance of women in bulbar-onset ALS.

The Babinski sign is a definitive sign of upper motor neuron disease, and its importance for the diagnosis of ALS has been re-emphasized by Rowland ${ }^{25}$, but not all ALS patients had Babinski sign in our series: this was present in only $21.8 \%$ (17/78) of them display it (Appendix). The absence of Babinski sign in ALS patients may possibly be a consequence of lower motor neuron involvement, with weakening of the toe extensor muscles ${ }^{26}$.

Fasciculations are found in nearly all ALS patients, but they are rarely a presenting symptom ${ }^{4}$. In our ALS patients, however, it represented only $24.4 \%$ (19/78) as onset symptom (Appendix). In the analysis of these cases, fasciculations were mostly present when bulbar region was also involved. In our series, 57 out $78(73.1 \%)$ ALS patients evidenced fasciculations when there was involvement of bulbar neurons. The relevant aspects to be mentioned are: (1) the distribution of fasciculations showed that they were predominant expression from areas with larger population of motor neurons such as the bulbar, cervical and lumbar regions, and (2) the contiguous areas (bulbar/cervical, cervical/ lumbar) were more prone to be the anatomic origin of fasciculations.

Summing up, the most peculiar aspects in our series of Brazilian ALS patients are the higher prevalence of young cases (juvenile and early-onset adult ALS), and the important presence of pain as initial symptom in these ALS patients. 


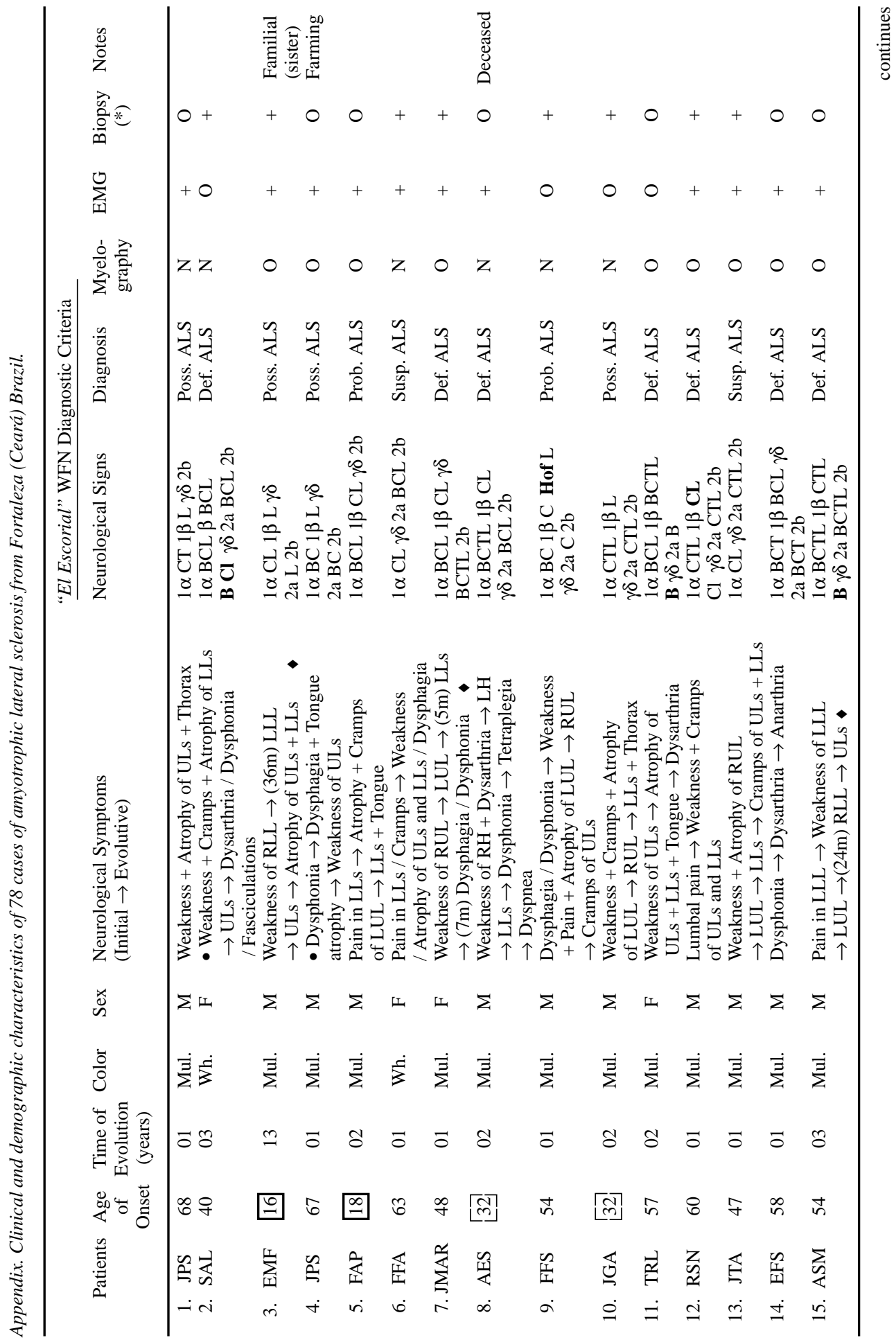




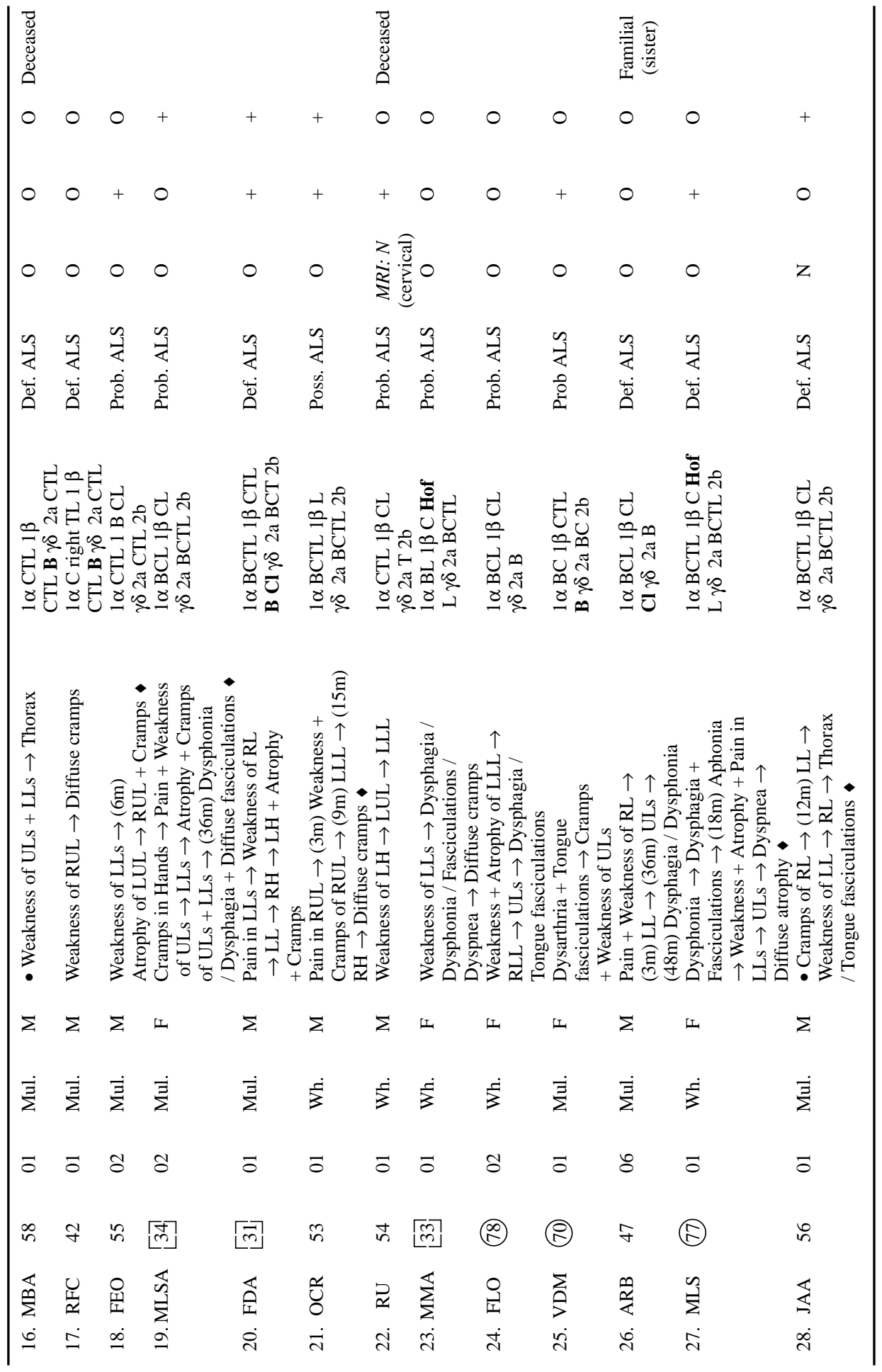




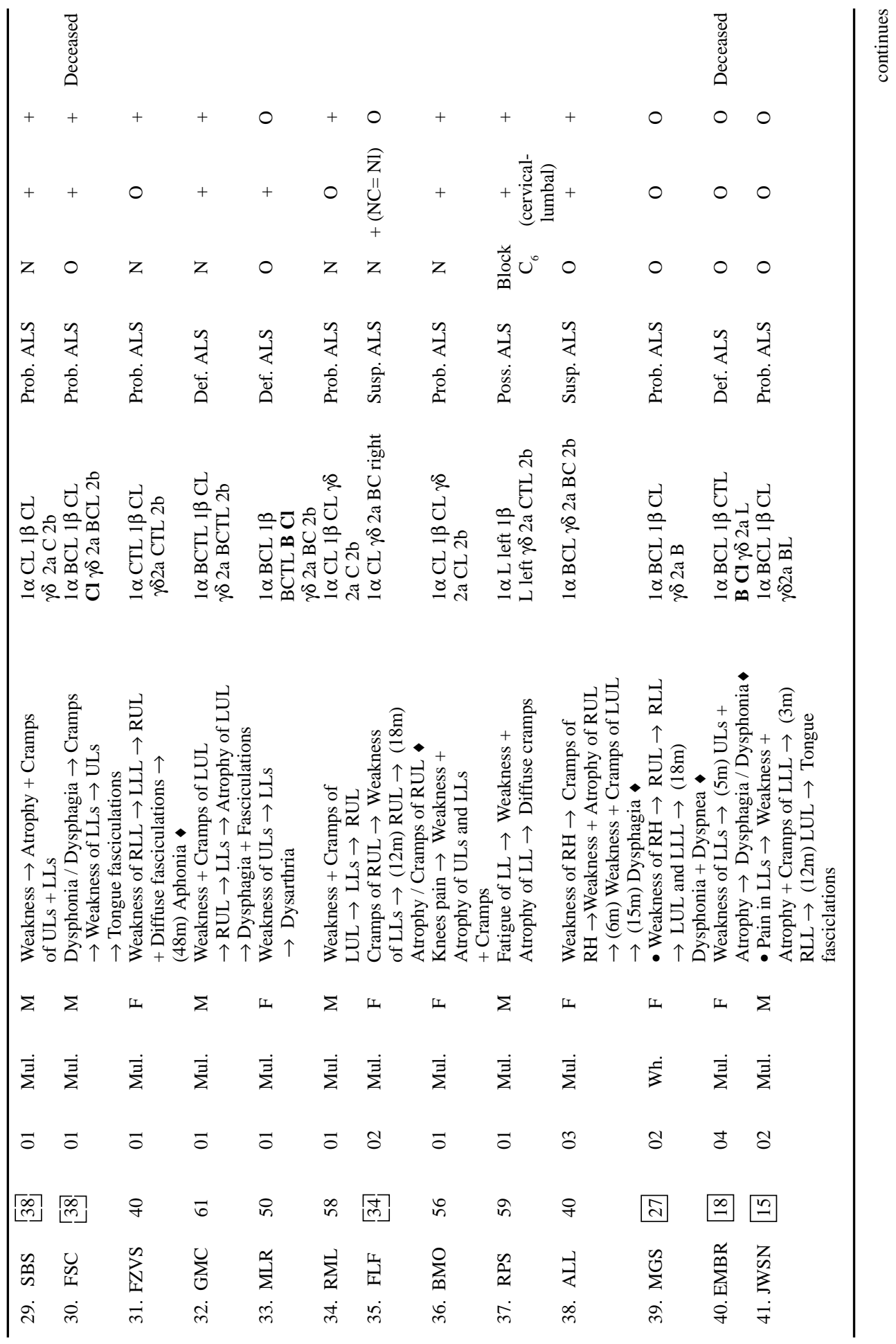




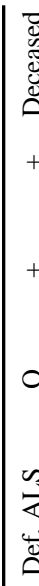

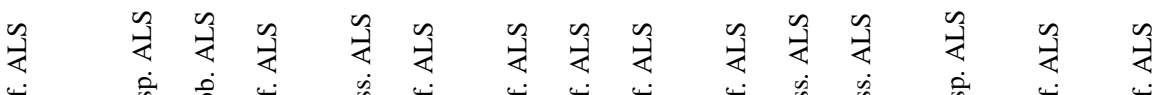

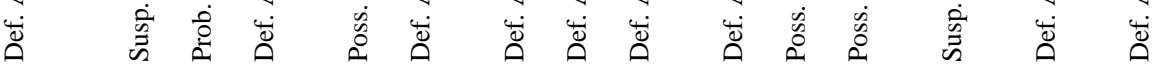

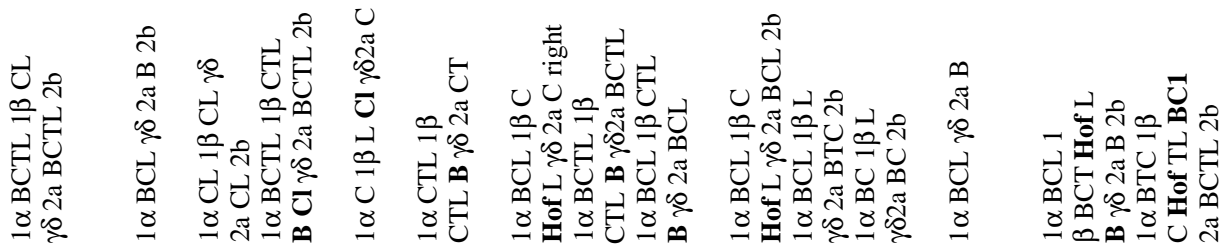

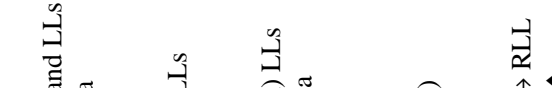

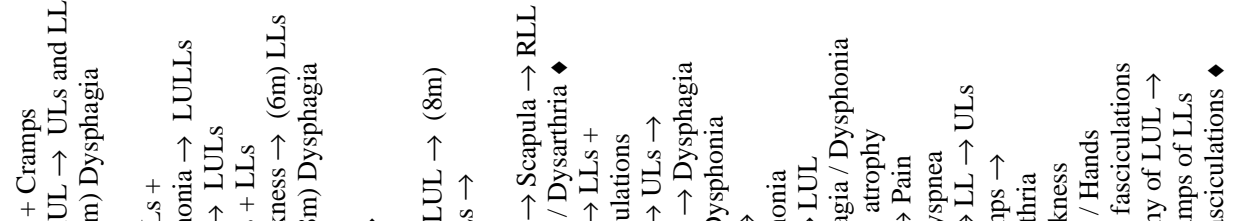

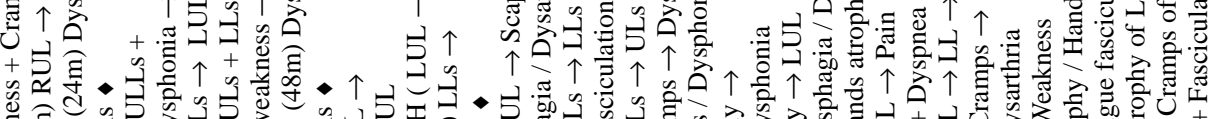

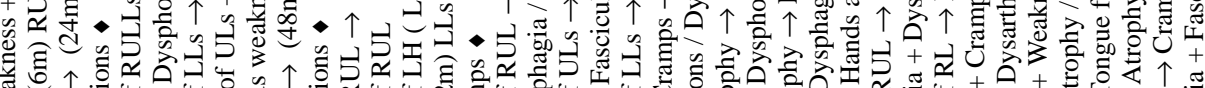
ॠ

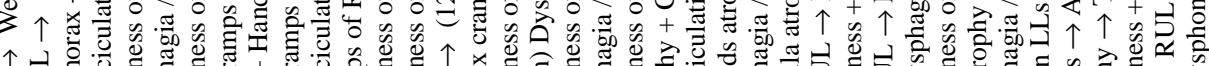

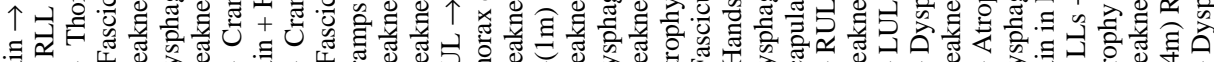

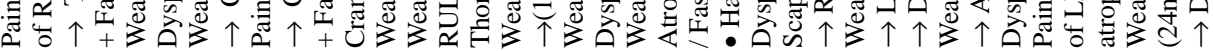

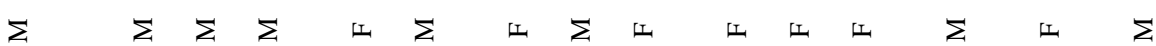

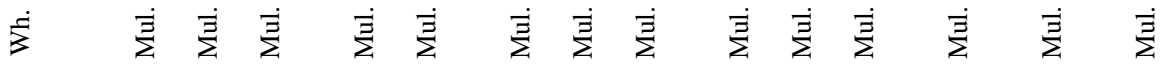

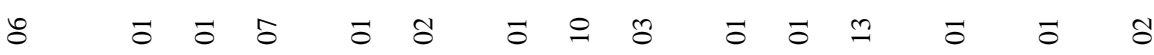

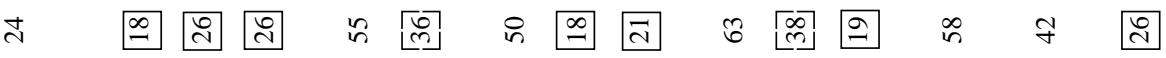

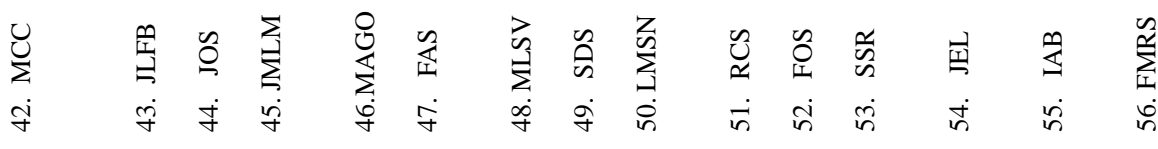




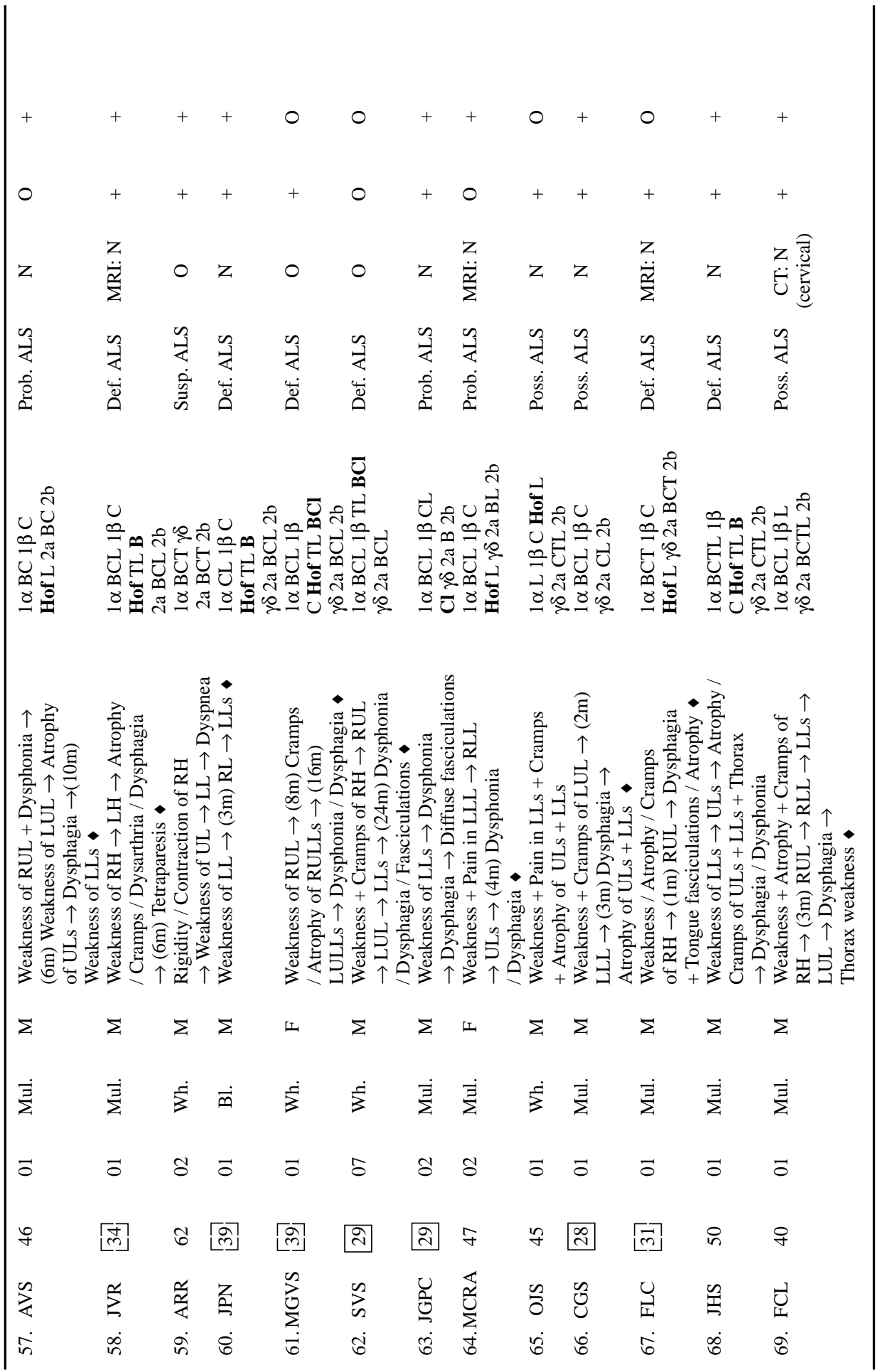




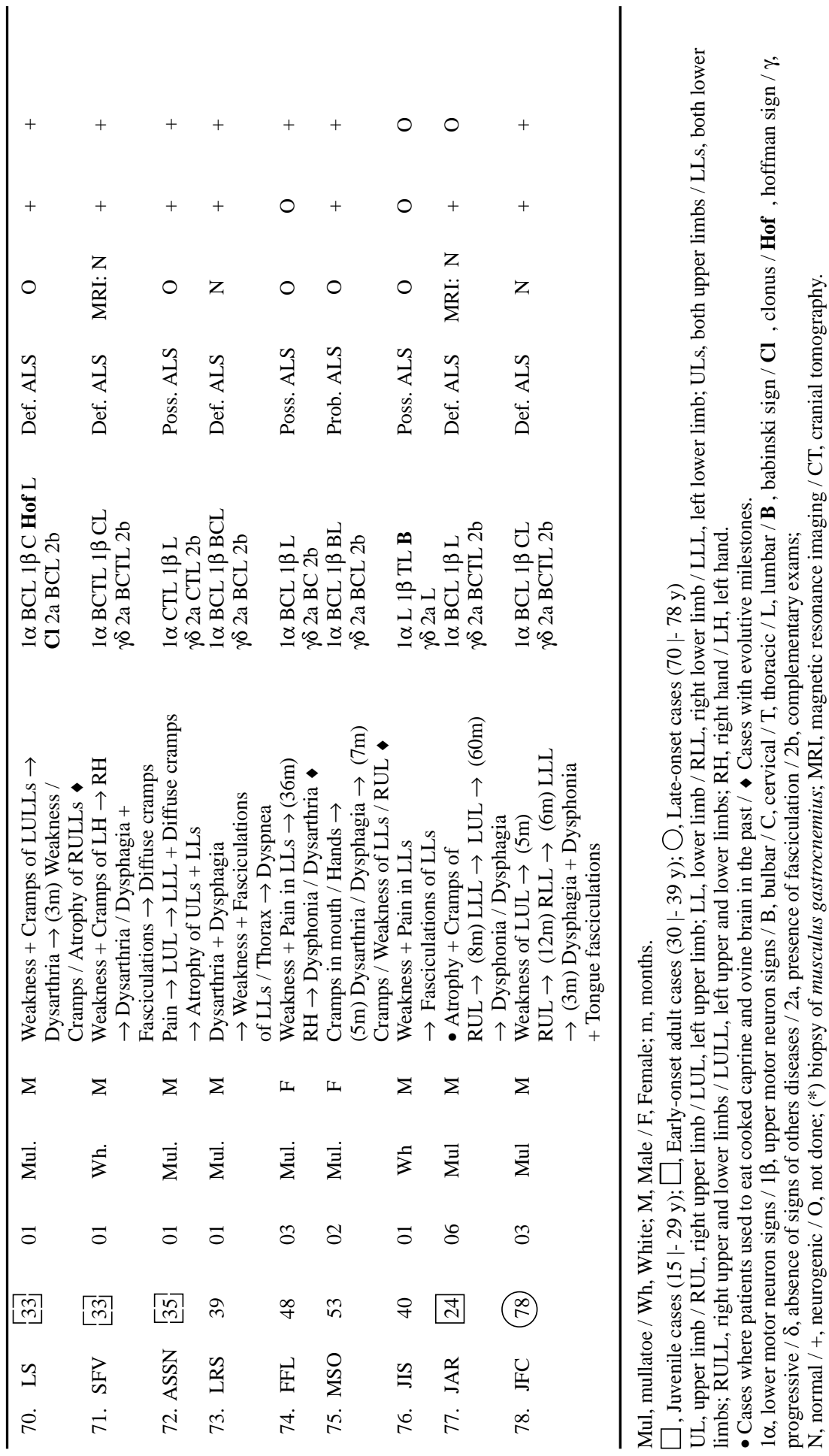




\section{REFERENCES}

1. Donohoe DJ, Brady B. Motor neuron disease: etiology, pathogenesis and treatment - a review. Irish J Med Sci 1996;165:200-209.

2. Alter M, Kurland LT, Molgaard CA. Late progressive muscular atrophy and antecedent poliomyelitis. In Rowland LP (ed.). Human motor neuron diseases. New York: Raven Press, 1982,303-309.

3. Salazar AM, Masters CL, Gajdusek DC, Gibbs CJ. Syndromes of amyotrophic lateral sclerosis and dementia: relation to transmissible Creutzfeldt-Jakob disease. Ann Neurol 1983;14:17-26.

4. Mitsumoto H, Chad DA, Pioro EP. Epidemiology. In Davis FA (Ed.). Amyotrophic lateral sclerosis. Philadelphia: FA Davis Company, 1998;18-33.

5. Plaitakis A, Caroscio JT. Abnormal glutamate metabolism in amyotrophic lateral sclerosis. Ann Neurol 1987;22:575-579.

6. Rosen DR, Siddique T, Pattersen D, et al. Mutations in $\mathrm{Cu} / \mathrm{Zn}$ superoxide dismutase gene are associated with familial amyotrophic lateral sclerosis. Nature, 1993;362: 59-63.

7. Garcia SH, Engelhardt JI, Appel SH, et al. Increased MEPP frequency as an early sign of experimental immune-mediated motoneuron disease. Ann Neurol 1990;28: 328-334.

8. Snyder SH, Bredt DS. Biological roles of nitric oxide in Scientific American, Special Issue. Medicine 1993;22-30.

9. El Escorial World Federation of Neurology Criteria for the Diagnosis of Motor Neuron Disease. J Neurol Sci 1994;124(Suppl):96-107.

10. Caroscio JT, Mulvihill MN, Sterling R, Abrams B. Amyotrophic lateral sclerosis - Natural history. Neurologic Clinics 1987:51-8.

11. Chazot F, Tabaraud F, Boulesteix JM, et al. Épidémiologie de la sclérose latérale amyotrophique en Limousin. Rev Neurol (Paris) 1989;145:408-410.

12. Berry RG, Chambers RA, Duckett S, et al. Clinicopathological study of juvenile amyotrophic lateral sclerosis. Neurology 1969;19:312.

13. Nishigaki S, Takahashi A, Matsuoka A. An autopsy case of sporadic juvenile amyotrophic lateral sclerosis. Clin Neurol 1971;11:400-506.

14. Gubbai SS, Kahana E, Zilber N et al. Amyotrophic lateral sclerosis: a study of its presentation and prognosis. J Neurol 1985;232:295-300.

15. Nelson JS, Prensky AL. Sporadic juvenile amyotrophic lateral sclerosis. Arch Neurol 1972;27:300-306.

16. Godoy JM, Skacel M, Balassiano SL, et al. Esclerose lateral amiotrófica - Variante distal dos membros inferiores. Arq Neuropsiquiatr 1991;49:321-325.

17. Kondo K, Hemmi I. Clinical statistics in 515 fatal cases of motor neuron disease. Neuroepidemiology 1984;3:129-148.

18. Li T-M, Alberman E, Swash M. Clinical features and associations of 560 cases of motor neuron disease. J Neurol Neurosurg Psychiatry 1990;53:1043-1045.

19. Haverkamp LJ, Appel V, Appel SH. Natural history of amyotrophic lateral sclerosis in a database population. Validation of a scoring system and a model for survival predication. Brain 1995;118:707-719.

20. Newrick PG, Langton-Hewer R. Motor neuron disease: can we do better? A study of 42 patients. Br Med J 1984;289:539-542.

21. Brooks BR, Sufit RL, De Paul R, De Tan Y, Sanjak M, Robbins J. Design of clinical therapeutic trails in amyotrophic lateral sclerosis. In Rowland LP (Ed.). Advances neurology: amyotrophic lateral sclerosis and other motor neuron diseases. New York: Raven Press, 1991,521-546.

22. Jokelainen M. Amyotrophic lateral sclerosis in Finland: 2. Clinical characteristics. Acta Neurol Scand 1977;56:194-204.

23. Norris F, Shepherd R, Denys E et al. Onset, natural history and outcome in idiopathic adult motor neuron disease. J Neurol Sci 1993;118:48-55.

24. Brooks BR. The role of axonal transport in neurodegenerative disease spread: a meta-analysis of experimental and clinical poliomyelitis compares with amyotrophic lateral sclerosis. Can J Neurol Sci 1991;18:435-438.

25. Rowland LP. Babinski and the diagnosis of amyotrophic lateral sclerosis. Ann Neurol 1993;33:108-109.

26. Landau WM, Clare MH. The plantar reflex in man, with special reference to some conditions where the extensor response is unexpectedly absent. Brain 1959;82:321-355. 